\title{
NOMINA INSTRUMENTI BLANDT KOMPOSITA I DANSK OG DERES POLSKE ÆKVIVALENTER
}

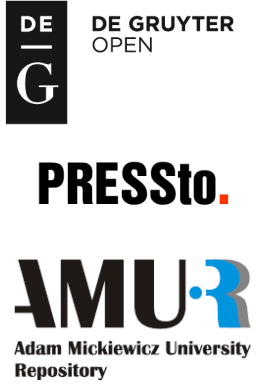

ANDRZEJ SZUBERT

Adam Mickiewicz University, Poznań

ABSTRACT. The article is an attempt at analyzing Danish nomina instrumenti among compounds and finding patterns of equivalence in Polish. The analysis of the collected corpus has shown that the Polish equivalents of the Danish compounds are not compounds but, with the exception of a minor group of derivates, they have the form of phrases. The analysis has shown patterns of regular Polish structures corresponding to the Danish compounds.

\section{INDLEDNING}

Nomina instrumenti er substantiver, der benævner redskaber og som regel dannes af verber (EJO, 1993:360). I nogle tilfælde kan de have samme morfologiske form som nomina agentis, jf. dan. aflaeser. Ifølge Metzlers Lexikon (1993:421f.) er de en semantisk bestemt underklasse af substantiver, der i de fleste tilfælde er afledt af verber, og de betegner et middel i en hændelse. De betegner altså redskaber, værktøjer o.lign., og set ud fra et orddannelsessynsvinkel kan de både være simple ord, derivater og komposita. Komposition er den mest overskuelige og mest produktive orddannelsestype i dansk og de andre germanske sprog. I polsk er den knap så produktiv, og man bruger ofte nominale ordgrupper eller derivater til at betegne det samme, som i dansk betegnes ved et kompositum. Jeg vil i det følgende prøve at sammenligne danske determinative komposita, der hører til klassen nomina instrumenti, med deres polske semantiske ækvivalenter. Hensigten med sammenligningen er at undersøge, hvilke strukturer i polsk der svarer til de danske komposita. Analysen er unilateral, og jeg går ud fra danske komposita. Dens udgangspunkt skal være, at de danske komposita stilles over 
for deres polske semantiske ækvivalenter. Som første skridt vil de danske komposita blive inddelt efter deres morfologiske opbygning. Den første inddeling er efter ordklasser (f.eks. substantiv + substantiv), hvorefter de inddeles efter de enkelte leds semantiske funktion. Under en semantisk funktion forstås i denne artikel den rolle, som leddet opfylder i konstruktionen (mere til det se Szubert, 2012). Funktionerne kan være f.eks. person, genstand, sted, o.a., og de er angivet på forkortelseslisten. På listen er der angivet flere semantiske funktioner, end der forekommer i de danske komposita, der er nomina instrumenti, men det syntes at være hensigtsmæssigt at vise dem alle sammen for at afgrænse hele problemstillingen. Disse kompositas semantiske struktur er sådan, at andetleddet (kerneleddet) betegner et instrument (redskab, værktøj o.l.), der er determineret af førsteleddet. Førsteleddet kan betegne en agens, et sted, et tidsrum m.m. og er adled i kompositummet.

I det følgende vil jeg præsentere resultatet af analysen, der ikke har som formål at være udtømmende, men skal vise, hvor forskelligt nomina instrumenti udtrykkes i dansk og polsk, og forhåbentlig vil bidrage til videre forskning inden for feltet.

\section{MORFOLOGISK STRUKTUR SUBSTANTIV + SUBSTANTIV}

Til denne gruppe hører komposita, hvor begge led er substantiver. Deres semantiske funktioner inden for kompositummet er dog forskellige, hvilket har indflydelse på de polske ækvivalenter.

$$
\text { 2.1. } \mathrm{K}\left[\mathrm{Sb}_{[\text {hum }]}+\mathrm{Sb}_{[\text {[obj] }}\right]
$$

I denne gruppe af danske komposita betegner førsteleddet en person, i dette tilfælde et nomen agentis, mens andetleddet betegner en genstand. Semantisk kan strukturen fortolkes, som at sidsteleddet "B er et objekt, der bruges af personen A", der er førsteled.

Strukturen kan parafraseres på følgende måde, som f.eks.:

gartnerkniv - kniv, som er beregnet/bestemt for gartnere / som bruges af gartnere'

murerske - 'ske, som er beregnet/bestemt for murere / som bruges af murere'

Ud fra den morfologiske struktur af substantivet murerske kunne man være i tvivl, om det drejer sig om et derivat, der betegner en ?kvindelig murer eller en ske, der bruges af en murer. Men her analyseres kun komposita, så den her anvendte fortolkning er den sidst nævnte.

Eksempler på denne struktur og deres polske ækvivalenter: 


\section{DANSK}

$\mathbf{K}\left[\mathbf{S} \mathbf{b}_{[\mathrm{hum}]}+\mathbf{S} \mathbf{b}_{[\mathrm{obj}]}\right]$ gartnerkniv

malerpistol

murerhammer

skraddersaks

skradderkridt

tagdakkerhammer

kokkekniv

tandlagebor

tandlaegespejl

\section{POLSK}

$\mathbf{O G}\left[\mathbf{S b}_{[\text {hum] }}+\mathbf{A d j}_{[\text {[ident] }}\right]$

nóż ogrodniczy

pistolet malarski

młotek murarski

nożyce krawieckie

kreda krawiecka

młotek dekarski

nóż kucharski

wiertto dentystyczne

lusterko dentystyczne

Som det fremgår af de ovennævnte eksempler, svarer det danske kompositum til en nominal ordgruppe i polsk, hvor det første element er et substantiv med et attribut $\mathrm{i}$ form af et efterstillet adjektiv, der er afledt af et nomen agentis. Rækkefølgen er ikke vilkårlig. De polske ordgrupper danner begreber og skal betragtes som helheder, hvis struktur er fast.

$$
\text { 2.2. } \mathrm{K}\left[\mathrm{Sb}_{[\mathrm{obj}]}+\mathrm{Sb}_{[\mathrm{obj}]}\right]
$$

Komposita, der opviser denne struktur, kan semantisk inddeles i to grupper. Den første gruppe af komposita består af led, hvor begge er genstande, men sidsteleddet $\mathrm{B}$ enten er et appellativ eller et nomen instrumenti, hvormed en handling, der semantisk er indeholdt i det, udføres på genstanden A. Sidsteleddet udgør et semantisk udgangspunkt for handlingen, f.eks. piberenser - 'instrument, som man bruger til at rense pibe med.' Alle sidsteled er afledt af verber. Den anden gruppe udgør komposita, i hvilke sidsteleddene ikke er afledt af verber, og de kan fortolkes således, at "B er et objekt, der bruges til forarbejdelse af A. Betydningen af førsteleddet A indskrænker anvendelsen af B”. Fordi analysen ikke går dybere ind på de enkelte leds morfologiske struktur, behandles begge grupper under samme struktur.

Strukturen kan parafraseres på følgende måde, som f.eks.:

$$
\begin{aligned}
& \text { piberenser - 'en renser, som man renser pibe med' } \\
& \text { vinduesvisker - 'en visker, som man visker vinduer med' } \\
& \text { rosensaks - 'saks, som man klipper roser med' } \\
& \text { brødkniv - 'kniv, som man skærer brød med' }
\end{aligned}
$$

Eksempler på denne struktur og deres polske ækvivalenter:

$$
\begin{aligned}
& \text { DANSK } \\
& \left.\mathbf{K}_{\text {[ }} \mathbf{S b}_{[o b j]}+\mathbf{S b}_{[o b j]}\right] \\
& \text { tømmersav }
\end{aligned}
$$

POLSK

$\mathbf{S}\left[\mathbf{S b}_{[0 \mathrm{bj}]}\right]$

trak 
Som ækvivalent til det danske kompositum bruges et simpelt ord i polsk.

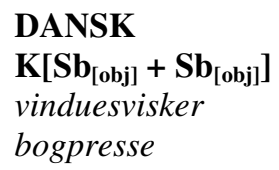

$\begin{array}{ll} & \text { POLSK } \\ \left.\text { OG }_{[} \mathbf{S b}_{[\text {obj] }}+\mathbf{A d j}_{[\mathbf{i d e n t}]}\right] \\ - & \text { wycieraczka samochodowa } \\ - & \text { prasa drukarska }\end{array}$

I disse tilfælde bruges der i polsk et substantiv, der svarer til kerneleddet i det danske kompositum, og et efterstillet adjektiv, der er afledt af et substantiv. I mange tilfælde svarer danske derivater på -er både til nomina instrumenti og nomina agentis. I dansk ville konteksten afgøre, om det drejer sig om det ene eller det andet. I polsk er antallet af suffikser, der udtrykker nomina agentis og nomina instrumentis noget større, hvilket kan være et problem i oversættelsen. Men det er ikke det væsentlige i denne undersøgelse.

DANSK
$\mathbf{K}_{\left[\mathbf{S} \mathbf{b}_{[0 \mathbf{j}]}+\mathbf{S b}_{[\mathbf{o b j}]}\right]}$
dåseåbner
piberenser
strømpebånd
haekesaks
rosensaks
brфdkniv
frugtkniv
neglesaks

\begin{tabular}{|c|c|}
\hline & POLSK \\
\hline - & $\begin{array}{l}\mathbf{O G}\left[\mathbf{S b}_{[0 \mathbf{b j}]}+\mathbf{P}+\mathbf{S b}_{[\mathbf{o b j}]}\right] \\
\text { otwieracz do puszek/konserw }\end{array}$ \\
\hline & czyścik do fajki \\
\hline & pas do pończoch \\
\hline & sekator do żywoptotu \\
\hline & nó̇yce do róż \\
\hline & noż do chleba \\
\hline & noż do owoców \\
\hline & nożyczki do paznokci \\
\hline
\end{tabular}

Som det kan ses på de polske konstruktioner, svarer de sidste elementer til adled i de danske komposita, med den forskel, at de forekommer i både singularis og pluralis. Der bruges udelukkende præpositionen do 'til', der styrer genitiv, og tilsvarende er de efterfølgende substantiver i genitiv, både i singularis og pluralis.
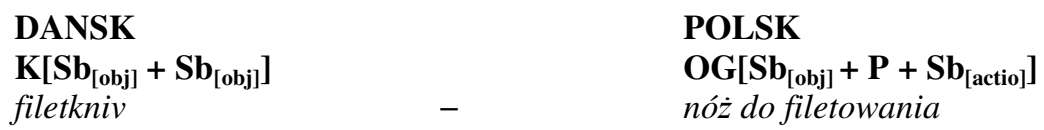

I dette tilfælde betegner den polske konstruktions sidste element et nomen actionis.

$$
\begin{aligned}
& \text { DANSK } \\
& \left.\mathbf{K}^{\mathbf{S} \mathbf{S b}_{[\text {obj] }}}+\mathbf{S b}_{[\text {obj] }}\right] \\
& \text { aggekoger }
\end{aligned}
$$

$\mathbf{P O L S K}$
$\mathbf{O G}\left[\mathbf{S b}_{\text {[obj] }}+\mathbf{P}+\mathbf{S b}_{\text {[actio] }}+\mathbf{S b}_{[\text {[obj] }}\right]$
urzadzenielaparat do gotowania jaj

Den polske ordgruppe afspejler en struktur, hvor det danske sidsteled forekommer som det første element efterfulgt af præpositionen do ('til') og 
substantivet, der betegner handlingen og er et nomen actionis, og et substantiv i genitiv, der bliver objekt for denne handling. Dette kunne gengives på dansk ved ?maskine til kogning af a g. Ved dette eksempel må der tilføjes, at der som ækvivalent til det danske aggekoger også forekommer polsk jajowar, der er en samdannelse, og som bruges på lige fod med de ovennævnte.

$$
\text { 2.3. } \mathrm{K}\left[\mathrm{Sb}_{[\mathrm{mat}]}+\mathrm{Sb}_{[\mathrm{obj}]}\right]
$$

Semantisk kan komposita, der hører til denne gruppe, parafraseres som "B er et objekt, som man udfører en handling med på materialet $\mathrm{A}$, eller $\mathrm{B}$ bruges til at forarbejde, producere eller opbevare A." I den første gruppe er handlingen indeholdt i selve B'ets betydning, f.eks. er en hårbørste 'en børste, man børster håret med’. I det følgende skal eksemplerne fra begge grupper behandles sammen.

Strukturen kan parafraseres på følgende måde, som f.eks.:

trasav - 'sav, som man saver træ med'

sneskovl - 'skovl til at skovle sne med'

nudelmaskine - 'maskine, som man laver nudler med'

tagstensanlag - 'anlæg, som man producerer tagsten på

Eksempler på denne struktur og deres polske ækvivalenter:

\section{DANSK}

$\mathbf{K}\left[\mathbf{S b}_{[\mathrm{mat}]}+\mathbf{S b}_{[\mathrm{bbj}]}\right]$ betonblander

vaffelautomat, vaffeljern
POLSK

$\mathbf{D}\left[\mathbf{S b} \mathbf{b}_{[o b j]}\right]$

betoniarka

waflownica

I begge tilfælde er derivaterne afledt af substantiverne, der er adled i de danske komposita.

\section{DANSK}

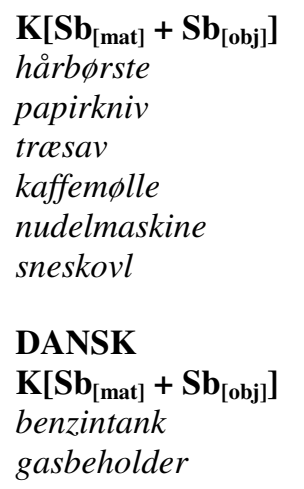

\section{POLSK}

$\mathbf{O G}\left[\mathbf{S b}_{[\mathrm{obj}]}+\mathbf{P}+\mathbf{S b}_{[\mathrm{mat}]}\right]$

szczotka do włosów

nóż do papieru

pita do drewna

mbynek do kawy

maszynka do makaronu

topata do śniegu

POLSK

$\mathbf{O G}\left[\mathbf{S b}_{[\mathrm{obj}]}+\mathbf{P}+\mathbf{S} \mathbf{b}_{[\text {mat }]}\right]$

zbiornik na benzyne

pojemnik na gaz 
I tilfældet af sneskovl har vi at gøre med to ækvivalenter og også to forskellige strukturer. Den første er som ovennæunt, mens den anden 'topata do odśnieżania' afspejles i:

DANSK

$\mathbf{K}\left[\mathbf{S b}_{[\mathrm{mat}]}+\mathbf{S b}_{[\mathrm{obj}]}\right]$ sneskovl
POLSK

$\mathbf{O G}\left[\mathbf{S b}_{[\mathrm{obj}]}+\mathbf{P}+\mathbf{S b}_{[\mathrm{actio}]}\right]$

topata do odśnieżania

I polsk gengives leddet sne med enten substantivet sne eller substantivet *afsnening, der er et nomen actionis.

DANSK

$\mathbf{K}\left[\mathbf{S b}_{[\mathrm{mat}]}+\mathbf{S b}_{[\mathrm{obj}]}\right]$

luftiliter
POLSK

$\mathbf{O G}\left[\mathbf{S b}_{[\mathrm{obj}]}+\mathbf{S b}_{[\mathrm{mat}]}\right]$

filtr powietrza

Det danske kompositum gengives af ordgruppen substantiv + substantiv $\mathrm{i}$ genitiv.

$$
\text { 2.4. } \mathrm{K}\left[\mathrm{Sb}_{[\text {phaenom }]}+\mathrm{Sb}_{[\text {obj] }}\right]
$$

Komposita med denne semantiske struktur kan parafraseres på følgende måde: "B er et objekt, med hjælp af hvilket fænomenet A opstår".

Strukturen kan parafraseres på følgende måde, som f.eks.:

musikinstrument - 'instrument, som man spiller musik på

lysmaskine - 'maskine, som man laver lys med'

Eksempler på denne struktur og deres polske ækvivalenter:

\section{DANSK}

$\mathbf{K}\left[\mathbf{S} \mathbf{b}_{[\text {[phaenom] }}+\mathbf{S b}_{[\text {obj] }}\right]$

musikinstrument
POLSK

$\mathbf{O G}\left[\mathbf{S b}_{[\mathrm{obj}]}+\mathbf{A d j}_{[\mathrm{ident}]}\right]$

instrument muzyczny

I nogle tilfælde gengives det danske adled i polsk ved hjælp af et adjektiv, der ikke har nogen ækvivalent i dansk. Adjektivet muzyczny, hvis indhold er forbundet med musik, findes ikke i dansk. På lignende måde som adjektiverne drewniany eller metalowy ('lavet af træ hhv. metal'), ligesom der findes gylden i forhold til guld. Der findes adjektiverne musikalsk/musisk og metallisk i dansk, men de betyder noget helt andet. Når adjektiverne som drewniany eller metalowy bruges som attributter foran substantiver i polsk, gengives de på dansk via komposita med substantiver trae hhv. metal. 


$$
\text { 2.5. } \mathrm{K}\left[\mathrm{Sb}_{[\mathrm{lok}]}+\mathrm{Sb}_{[\mathrm{obj}]}\right]
$$

De danske komposita med denne struktur skal fortolkes sådan, at "B er et objekt (instrument), der bruges på stedet A". Dette er et bestemmelsessted, hvilket ikke betyder, at genstanden ikke kan bruges andre steder, men den er blevet konstrueret og beregnet til at blive brugt det bestemte sted.

Strukturen kan parafraseres på følgende måde, som f.eks.:

køkkenkniv - 'kniv, som man bruger i køkkenet'

havekniv - 'kniv, som man bruger i haven'

Eksempler på denne struktur og deres polske ækvivalenter:

\section{DANSK}

$\mathbf{K}\left[\mathbf{S} \mathbf{b}_{[\mathrm{lok}]}+\mathbf{S b}_{[\mathrm{obj}]}\right]$

køkkenkniv

havekniv

havebord

skolebank

haveredskab

\section{POLSK}

$\mathbf{O G}\left[\mathbf{S b}_{[\mathrm{obj}]}+\mathbf{A d j} \mathbf{j}_{[\text {ident }]}\right]$

nóż kuchenny

nóż ogrodowy

stót ogrodowy

tawka szkolna

narzędzie ogrodowe

Førsteleddet i de danske komposita betegner et sted, der gengives i polsk ved et efterstillet adjektiv, der er afledt af samme substantiv, der betegner et sted i dansk.

$$
\text { 2.6. } \mathrm{K}\left[\mathrm{Sb}_{[\mathrm{temp}]}+\mathrm{Sb}_{[\mathrm{obj}]}\right]
$$

Disse komposita betegner "objekter B, der bruges eller burde bruges i bestemt tidsrum, eller på bestemt tid A".

Strukturen kan parafraseres på følgende måde, som f.eks.:

natpotte - 'potte, som man bruger om natten'

daglygte - 'lygte, som man bruger om dagen'

Eksempler på denne struktur og deres polske ækvivalenter:

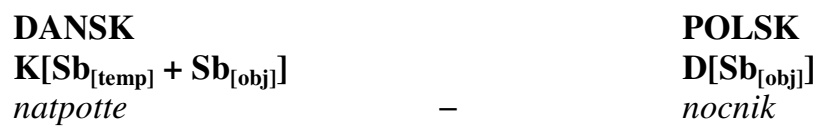

Det polske ækvivalent er et derivat afledt af leksemet noc ('nat'), der er bestemmerled i det danske kompositum. 
DANSK

$\mathbf{K}\left[\mathbf{S} \mathbf{b}_{[\text {temp] }}+\mathbf{S} \mathbf{b}_{[\mathrm{obj}]}\right]$ natbus

årskort
POLSK

$\mathbf{O G}\left[\mathbf{S b}_{[\text {obj] }}+\mathbf{A d j} \mathbf{j}_{[\text {ident }]}\right]$ autobus nocny

bilet roczny

$$
\text { 2.7. } \mathrm{K}\left[\mathrm{Sb}_{[\text {[actio] }}+\mathrm{Sb}_{[\text {obj] }}\right]
$$

Denne gruppe omfatter komposita, der kan fortolkes på følgende måde: "B er en genstand, et materiale, der bruges til at udføre handlingen A".

\section{DANSK}

$\mathbf{K}\left[\mathbf{S} \mathbf{b}_{[\mathrm{actio}]}+\mathbf{S} \mathbf{b}_{[\mathrm{obj}]}\right]$ impragneringsmiddel

opvaskemaskine

$\begin{array}{ll} & \text { POLSK } \\ & \mathbf{D}_{\text {SSb }} \\ - & \text { impregnat }] \\ - & \text { zmywarka }\end{array}$

POLSK

zmywarka

De danske bestemmerled er nomina actionis. Til det første eksempel findes der også en anden polsk ækvivalent, der indeholder dette nomen actionis:

\section{DANSK}

$\mathbf{K}\left[\mathbf{S b}_{[\mathrm{actio]}}+\mathbf{S} \mathbf{b}_{[\mathrm{obj}]}\right]$

impragneringsmiddel
POLSK

$\mathbf{O G}\left[\mathbf{S b} \mathbf{b}_{[\mathrm{obj}]}+\mathbf{P}+\mathbf{S b}_{[\mathrm{actio}]}\right]$

środek do impregnacji

Det danske kompositum opvaskemaskine svarer normalt til polsk zmywarka. Den kan på polsk også hedde maszyna do zmywania naczyń og viser strukturen:

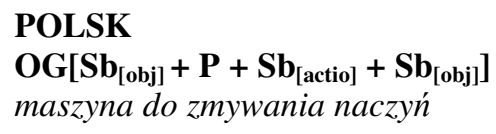

POLSK

$\mathbf{O G}\left[\mathbf{S b}_{[\text {obj] }}+\mathbf{P}+\mathbf{S} \mathbf{b}_{[\text {[actio] }}+\mathbf{S} \mathbf{b}_{[\text {[obj] }}\right]$

maszyna do zmywania naczyń

\section{MORFOLOGISK STRUKTUR VERBUM + SUBSTANTIV}

Denne gruppes komposita består af et verbum som førsteled og substantiv som sidsteled. De kan fortolkes på den måde, at sidsteleddet "B, som kan være et materiale eller en genstand, bruges til udførelsen af hændelsen A, eller muliggør tilstanden A".

Strukturen kan parafraseres på følgende måde, som f.eks.:

$k \phi l e v a n d$ - 'vand, som bruges til at køle med'

vaskepulver - 'pulver, som man bruger til at vaske med'

skrivemaskine - 'maskine, som man skriver på'

liggevogn/sovevogn - 'vogn, som bruges til at ligge/sove i' 
Eksempler på denne struktur og deres polske ækvivalenter:

\begin{tabular}{|c|c|c|}
\hline $\begin{array}{l}\mathbf{K}\left[\mathbf{V} \mathbf{b}_{[\text {actio] }]}+\mathbf{S b}_{[\mathbf{o b j}]}\right] \\
\text { barberblad }\end{array}$ & - & $\begin{array}{l}\mathbf{S}\left[\mathbf{S b}_{[\mathbf{o b j}]}\right] \\
b r z y t w a\end{array}$ \\
\hline DANSK & & POLSK \\
\hline $\mathbf{K}\left[\mathbf{V b}_{[\text {actio] }}+\mathbf{S} \mathbf{b}_{[\text {mat }]}\right]$ & & $\mathbf{D}\left[\mathbf{S b}_{[\text {mat }]}\right]$ \\
\hline blegevand & - & wybielacz \\
\hline vaskemaskine & - & pralka \\
\hline
\end{tabular}

I dette tilfælde kan det danske kompositum oversættes med det ovennævnte derivat eller med en ordgruppe som nedenunder - środek wybielający. I polsk er begge leksemer synonyme.

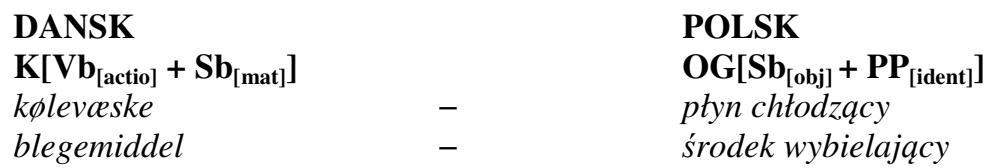

I de ovennævnte grupper forekommer komposita med et verbum som første led, og deres polske ækvivalenter kan enten være et derivat eller en ordgruppe med et substantiv og et efterstillet præsens participium. Participiet er afledt af et nomen actionis.

Den følgende gruppe af danske komposita består af et verbum og et substantiv, der er bruges til at udføre handlingen eller muliggør stilstanden A, der er udtrykt $\mathrm{i}$ verbet. I polsk er det derivater, der ikke nødvendigvis er afledt af verber.

DANSK

$\mathbf{K}\left[\mathbf{V} \mathbf{b}_{[\text {actio] }}+\mathbf{S} \mathbf{b}_{[\mathbf{o b j}]}\right]$

hafteklammer

vakkeur

boremaskine

høvlebank

drejebank

liggevogn

sфgemaskine

proveglas

måleglas

spadserestok

stiksav

trakgardin

trilleb $\phi r$
POLSK

$\mathbf{D}\left[\mathbf{S b}_{[0 b j]}\right]$

zszywacz

budzik

wiertarka

strugarka

tokarka

kuszetka

wyszukiwarka

probówka

menzurka

laska

wyrzynarka

zastona, kotara

taczka 
DANSK

$\mathbf{K}\left[\mathbf{V} \mathbf{b}_{[\text {actio] }}+\mathbf{S} \mathbf{b}_{[\text {obj] }}\right]$

høvlejern

surfbrat

målebånd

liggevogn

spiseske

\section{POLSK}

$\mathbf{O G}\left[\mathbf{S b}_{[\mathrm{obj}]}+\mathbf{A d j}_{[\text {[ident }]}\right]$

strug stolarski

deska surfingowa

taśma miernicza

wagon kuszetkowy

tyżka stołowa

Eksemplet liggevogn er placeret to steder i analysen, fordi leksemet kan gengives med to ækvivalenter i polsk - en ordgruppe substantiv + adjektiv eller et derivat. Det samme gælder for kompositummet spiseske, der kan gengives i polsk som ordgruppe $\mathrm{Sb}+\mathrm{Adj}$ (tyzka stołowa), eller $\mathrm{Sb}+\mathrm{P}+\mathrm{Sb}$ (byżka do zupy).

\section{DANSK}

$\mathbf{K}\left[\mathbf{V} \mathbf{b}_{[\mathrm{actio]}}+\mathbf{S \mathbf { b } _ { [ \mathrm { obj } ] } ]}\right.$ spiseske

DANSK

$\mathbf{K}\left[\mathbf{V} \mathbf{b}_{[\text {actio] }}+\mathbf{S} \mathbf{b}_{[\text {obj] }]}\right]$ skrivemaskine sprøjtepistol

liggestol laesebriller

DANSK

$\mathbf{K}\left[\mathbf{V b} \mathbf{b}_{\text {[actio] }}+\mathbf{S b}_{[\text {obj] }}\right]$ torrestativ
POLSK

$\mathbf{O G}\left[\mathbf{S b}_{[o b j]}+\mathbf{P}+\mathbf{S b}_{[\mathrm{obj}]}\right]$

tyżka do zupy

POLSK

$\mathbf{O G}\left[\mathbf{S b}_{[\text {obj] }}+\mathbf{P}+\mathbf{S b}_{[\text {actio] }]}\right]$

maszyna do pisania

pistolet do malowania

fotel do leżenia

okulary do czytania

\section{POLSK}

$\mathbf{O G}\left[\mathbf{S b}_{[\text {[obj] }}+\mathbf{P}+\mathbf{S b}_{[\text {actio] }}+\mathbf{S} \mathbf{b}_{[\text {obj] }}\right]$

stojak do suszenia prania

Denne gruppe er rig på strukturer. Her har vi derivater, der er nomina actionis afledt af verber, der svarer til de i danske komposita optrædende førsteled. Der er ordgrupper, der består af et substantiv og et efterstillet adjektiv. Der forekommer også ordgrupper med et substantiv og præpositionen do samt efterstillet substantiv i genitiv, der betegner en genstand. Der findes også efterstillede substantiver i genitiv, der er nomina actionis, og til sidst strukturer med et substantiv og præpositionen do efterfulgt af et substantiv i genitiv (nomen actionis) samt et substantiv i genitiv, der er genstand for den i nomen actionis udtrykte handling.

\section{MORFOLOGISK STRUKTUR ADJEKTIV + SUBSTANTIV}

Komposita, som hører til denne gruppe, har strukturen $\mathrm{Sb}+$ Adj. Adjektivet har her kun én semantisk funktion, nemlig identifikativ, dvs. en beskrivende en. 
Strukturen kan parafraseres på følgende måde, som f.eks.:

skråtag - 'tag, der er skråt'

langbank - 'bænk, der er lang'

Eksempler på denne struktur og deres polske ækvivalenter:

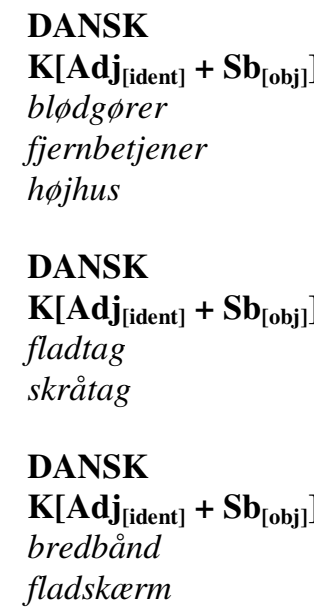

\begin{tabular}{|c|c|}
\hline & POLSK \\
\hline & $\mathbf{D}\left[\mathbf{S b}_{[\mathbf{o b j}]}\right]$ \\
\hline- & zmiękczacz \\
\hline- & pilot \\
\hline- & wieżowiec \\
\hline & POLSK \\
\hline & $\mathbf{O G}\left[\mathbf{S b}_{[\text {obj] }]}+\mathbf{A d j} \mathbf{j}_{[\text {ident }]}\right]$ \\
\hline- & dach płaski \\
\hline- & dach spadzisty \\
\hline & POLSK \\
\hline & $\mathbf{O G}\left[\mathbf{A d j}_{[\text {ident }]}+\mathbf{S b}_{[o b j]}\right]$ \\
\hline & szerokie pasmo \\
\hline & ptaski ekran \\
\hline
\end{tabular}

Som det kan ses på eksemplerne i denne gruppe, kan adjektivet $\mathrm{i}$ de polske ækvivalenter både være præ- og postponeret. I mange tilfælde er det forbundet med, at den efterstillede position af adjektivet bruges i begreber, dvs. helt leksikaliserede leksemer, hvor rækkefølgen ikke kan ændres, som f.eks. i skråtag - dach spadzisty, javnstrøm - prad staty, vekselstrøm prad zmienny m.m. Den omvendte rekkefølge er mulig i polsk, dog med præg af talesproget og ikke som et fagord. Det er i så fald beskrivende og udgør ikke et leksem. I andre tilfælde er rækkefølgen betydningsdifferentierende i polsk, for historyczne wydarzenie - historisk begivenhed betyder en begivenhed af meget stor vigtighed, mens ordgruppen med omvendt rækkefølge, dvs. wydarzenie historyczne, betyder, at en begivenhed har fundet sted i historien. Det er svært at påpege, hvornår danske komposita med adjektiv som adled, skal oversættes til polsk med en præ- eller postponeret postition af adjektivet. Det kan dog siges, at den nok mest frekvente rækkefølge er med postponeret adjektiv. Det drejer sig dog som regel om leksikaliserede begreber, og selv om det er ordgrupper, udgør de leksemer og skal semantisk betragtes som simple ord. 


\section{SAMMENFATNING}

Som det fremgår af det fremstillede materiale, svarer de danske komposita, der betegner nomina instrumenti, i langt de fleste tilfælde til nominale ordgrupper i polsk. I enkelte tilfælde havde vi at gøre med et simpelt ord og i lidt større omfang med derivater. Der blev ikke fundet et eneste eksempel på et kompositum i polsk, hvilket ikke betyder, at der ikke findes nomina instrumenti i polsk, der er komposita. Som eksempel kan nævnes glebogryzarka (direkte oversat *jordbider), der i dansk svarer til et derivat kultivator. Og omvendt findes der også nomina instrumenti i dansk, der ikke er komposita, men simple ord eller drivater, men det var ikke hensigten at analysere alle nomina instrumenti. Som nævnt i indledningen, blev de danske komposita inddelt i tre grupper efter deres morfologiske opbygning. Den første gruppe afspejler strukturen substantiv + substantiv og er den mest talrige. De danske komposita gengives i polsk igennem simple ord, derivater og nominale ordgrupper med strukturer: substantiv + substantiv i genitiv, substantiv + adjektiv, substantiv + adjektiv + substantiv i genitiv, substantiv + præposition $d o\left(\right.$ 'til' $\left.^{\prime}\right)+$ substantiv i genitiv, substantiv + præposition $n a$ ('til') + substantiv i akkusativ, substantiv + præposition do ('til') + substantiv i genitiv + substantiv i genitiv. I gruppen med strukturen verbum + substantiv forekommer kun fire og ikke syv strukturer som ved den ovennævnte med den forskel, at de tre ud af fire er de samme som i den første gruppe, og at der findes én struktur mere, nemlig substantiv + præsens participium, hvilket synes at være plausibelt, fordi participierne er afledt af verber og svarer til de danske verber. Den sidste gruppe er den mest beskedne og viser kun to strukturer: adjektiv + substantiv og substantiv + adjektiv. I de første tilfælde er rækkefølgen kun substantiv + adjektiv, hvilket indebærer, at den pågældende ordgruppe betragtes som en helhed, ligesom det er i tilfælde af et kompositum i dansk. Ordgrupperne i polsk må betragtes som leksikalske ordgrupper i modsætning til syntaktiske ordgrupper. Strukturen adjektiv + substantiv forekommer kun, når et dansk kompositum består af et adjektiv og et substantiv. Semantisk skal de polske ækvivalenter også betragtes som leksikaliserede helheder.

Undersøgelsen har vist, at de danske komposita, der er nomina instrumenti, gengives på polsk i form af først og fremmest ordgrupper med et substantiv og et efterstillet adjektiv eller et substantiv, præpositionen ' $d o^{\prime}$ 'og et substantiv. Det fælles ved de polske konstruktioner er, at uanset, hvor mange elementer der forekommer efter det første substantiv, der svarer til kerneleddet i det danske kompositum, danner de alle sammen et attribut til dette substantiv, der er kernen i strukturen. Det samme gælder for det foranstillede adjektiv. 


\section{FORTEGNELSE OVER FORKORTELSER}

A - kompositummets førsteled

abstr (abstractum) - betegner abstrakta (f.eks. følelser, iagttagelser)

actio (actio) - betegner hændelser, processer, handlinger, forløb

Adj - adjektiv

anim (animal) - betegner dyr

B - kompositummets sidsteled

$\mathrm{D}$ - derivat

EJO - Encyklopedia językoznawstwa ogólnego

hum (humanus/homo) - betegner mennesker

ident (qualitas) - betegner egenskaber

$\mathrm{K}$ - kompositum

lok (locativum) - betegner rum, steder

mat (materies) - betegner materialer

mod (modale/modus) - betegner modus, måde

obj (res) - betegner fysiske objekter, genstande

OG - ordgruppe

$\mathrm{P}$ - præposition

phaenom (phaenomenum) - betegner fænomener (fysiske fænomener som lyd, lys, vind)

plant (planta) - betegner planter

PP - præsens participium

$\mathrm{S}$ - simpelt ord

$\mathrm{Sb}-$ substantiv

status (status) - betegner tilstande

temp (temporale) - betegner temporalia

$\mathrm{Vb}-$ verbum

\section{LITTERATUR}

Den Danske Ordbog online (http://ordnet.dk/ddo/)

Encyklopedia językoznawstwa ogólnego (1993). Wrocław, Warszawa, Kraków: Zakład Narodowy im. Ossolińskich.

Metzler Lexikon Sprache (1993). Stuttgart, Weimar: Verlag J.B. Metzler.

Szubert, A. (2012). Zur internen Semantik der Nominalkomposita im Dänischen. Poznań: Wydawnictwo Naukowe UAM.

\section{Andrzej Szubert}

Uniwersytet im. Adama Mickiewicza w Poznaniu

Katedra Skandynawistyki

Collegium Novum

al. Niepodległości 4

61-874 Poznań

Poland

szubert@amu.edu.pl 